\title{
Children Should Not Be Silenced
}

\author{
Alina Georgeta Mag \\ Department of Private Law and Educational Studies, University “Lucian Blaga” of Sibiu, Sibiu, Romania \\ Email: magalina@gmail.com
}

Received 11 February 2014; revised 15 March 2014; accepted 30 March 2014

Copyright (C) 2014 by author and Scientific Research Publishing Inc.

This work is licensed under the Creative Commons Attribution International License (CC BY). http://creativecommons.org/licenses/by/4.0/

c) (i) Open Access

\section{Abstract}

Early Years services in Romania have, until recently, lacked any form of national financial support. Early childhood practitioners are very low paid and the investments in training programs are insufficient. The impact on children should be considered and policy decisions should be taken, in order to grow the opportunities for training. In a world affected by financial crises, attitudes about children's needs are very important. This research evaluates if the voices of children in Romanian preschools are heard and proposes new educational policy in order to train practitioners for preschools. The purpose of the study is to involve practitioners and parents in the Early Years in an experimental training program called: "Voices of Children in Romania". We discovered that according to the traditional attitudes of Romanian parents and practitioners, children's voices are rarely taken into consideration. After the new training program was put into practice in preschools and homes, teachers and parents started to give more attention to children's voices and children's wellbeing was improved. The study is relevant in order to increase public attention to the professional development of the early childhood workforce as a factor that can contribute to a healthy childhood.

\section{Keywords}

Children's Wellbeing, Children's Voice, Professional Training, Reflective Practice

\section{Introduction}

All those working in the early years are all too aware of the rapid changes in policy, provision and practice in recent years. Children can change the world and education can change the way children perceive the world. In recent times we have seen changes in attitudes and attention to childhood. Recent years have seen the agreement of new international conventions, national bodies established and waves of regional and local initiatives all concerning children (Jones, 2009: p. 1). Radical questions are challenging long-held attitudes and beliefs about children: "Who are the children of today?", "How well do we understand children's needs?" The impetus for 
change is energetic and powerful.

Focusing on the lives of modern children can be a disquieting experience (Collins \& Foley, 2008: p. 3). Recent studies demonstrated that if children's educational needs are not fulfilled in the first years of life, serious gaps will appear in their development. The attitudes of adults, in all their different roles and relationships, affect children deeply. In the past much research treated children as objects: research was done on them, with the agenda and framework set purely by adults. Children have been silenced and excluded in many ways, because they were underestimated. In fact children are born with sophisticated capacities and adults should not restrict or limit their potential. Adults should work with children in new ways driven by a rights perspective. Children's voices need to be heard.

Romania is facing huge economic and political crises. The level of the economic stress is high, affecting both adults and children. It is therefore appropriate to explore the conditions of childhood in Romania today and ask how far the current anxiety about children's wellbeing is justified. The attitudes, opinions and lived experiences of Romanian children are at risk of not being valued so this research is focused on the opportunities and challenges created by listening to children.

\section{Problem Statement}

Before and since the Romanian revolution in 1989, children were suffering in Romania both in institutions and on the street. The situation is much better now but still the gap is huge between education of children in the former communist countries and children in the West. The quality of education is reflected in the social and political life of the country. Recent concerns are about the pressures to which today's children are subjected and the undesirable values, influences and experiences to which many are exposed in their daily lives. They have a profound impact on both patterns of work and the structure of the family, and consequently have affected the daily rhythm of children's lives at home and in preschools. Nevertheless, children have to cope.

The state has been unable to make positive changes to the education system in the last 20 years. It is only the investment in teacher training which can make a difference. Because of the lack of funding, the lack of knowledge and the lack of motivation of the teachers, children are often neglected or abused, especially at young ages. This situation is impacting on their entire intellectual, emotional and social development.

Many studies assert that children's mental and emotional health depends on the efficiency of the relationships that adults construct with them from conception (Cable, 2010). Parents and teachers are responsible for children's health and development. They should relate to the children in order to promote children's wellbeing. For many years, children's competencies were underestimated by adults. Adults controlled and influenced their lives completely and children were considered totally dependent. However, new studies into children's competencies from birth changed the vision on children's potential and needs (Johnson, 2010). In the century of change, adult's abilities are considered to be vital, such as supporting children's emotions, understanding stressful situations, developing relationships and communication skills, promoting critical and creative thinking and demonstrating empathy. Children's collective voices can contribute to the development of positive adult-child relationship (Foley \& Leveret, 2008: p. 161).

Politicians and the media debate children's educational needs. Nevertheless questions such as "Are teachers prepared to build educational relationships that are effective and adapted to the psychology of today's children?", "Are children still seen and not heard?”, "How can children's voice be prioritized?" still elicit vague responses. If we observe any preschool in Romania we will discover that the relationships between teachers and parents is more administrative than educationally based; in many cases it is superficial or distant, and there is no time to endow children with life-skills that they really need, because the curriculum is too complex or teachers are not adequately trained. A widespread belief, especially among parents, that childhood has become more stressful is another issue that affects children's lives. Anxieties among teachers because of the financial crisis, too many changes brought by educational reform, concerns about many parents failing to discipline their children effectively or accept the responsibility for their behavior in and out of preschools and home, the growing number of children with behavioral and emotional disorders are important issues in today's early year's education in our country.

Children in many countries and within different cultures are living fulfilled lives. However, a significant number of other children experience life very differently. The analysis of findings in many researches so far which have tried to name, and to understand what is going wrong reveals interacting forces that create unhappiness and 
injustice for children. The interplay between large scale influences such as poverty, racism and sexism, their role in creating social exclusion and the macro processes of policy, law and national services provision are reflected in the daily encounters of children in their homes, the streets, the playgrounds and the preschools or schools (Jones, 2009).

\section{Purpose of the Study}

The key argument of this study is that the teacher-child educational relationship must be adequate and rebuilt taking account of contemporary child psychology research. If children's voices are not heard and they do not benefit early from educational relationships that fulfill their emotional needs, the impact on their development will be negative and hard to recover. Innovation is required in order to fulfill children's needs and rights in the educational system of today.

This research evaluates whether adults' attitudes still affect children's lives in Romania and if the voices of children in Romanian preschools are heard. The focus of the research is how to train teacher's attitudes towards children's voice and children's needs. The purpose of the study is to involve practitioners and parents in the Early Years in an experimental training program called: "Voices of children in Romania" and to propose new educational policy in order to train practitioners for preschools. Training teachers and parents to listen to children's voices and to explore the educational needs of children is a real challenge in the context of Romania today.

The research objectives were: assessing the voice of children in their relationships with preschool teachers; building a new training program; applying the program to the experimental groups; developing tools to assess children's and teachers performances; identifying the relating type which has the biggest potential to promote children's voice and wellbeing.

The research hypothesis is: if teachers construct educational relationships from the perspective of the new program then: children's wellbeing will be increased, children's social and emotional skills will be increased and the frequency of disruptive behavior will be reduced; if teachers are trained with the new program then: their relational performances will be improved and their confidence in promoting children's voice and wellbeing will be increased.

\section{Methods}

The research started with a systematic review of current guidelines in teacher training from Early Education frameworks available nationally and internationally and of the competencies required for preschools teachers today. The next step was an analysis of the current situation and needs for training in the Romanian system. The research methods were: experiment, observation, surveys and case studies. The techniques used were: focus groups, photos and video film. Every photo and film was made with parent's official approval, also with preschools teachers' informed consent. Video films bring authenticity to the entire research.

Investigating a group of parents and practitioners in different geographical areas in Romania the research used first focus groups, surveys and observations in order to evaluate their attitudes towards children's educational needs and rights. The next step was the implementation of the experimental training program about children's voices from birth. The mission of the program was to support parents and professionals in raising socially and emotionally healthy children. Different types of surveys were also used for every category of participant in the program during the experiment. Another relevant method was the observation of how educational relationships between teachers and children functioned before, during and after the program implementation.

An innovation tool based on emotional intelligence components was designed to evaluate teachers' level of relationship skills and to identify the relating types used by teachers in practice. Four types of relationship were identified: balanced type, rigid type, nervous type and anxious type.

The research group was represented by 42 teachers, 142 children and 142 parents that were involved in the experiment. Seven preschools from Sibiu and four preschools from Brasov were involved in the research. The selection for the experiment was based on participants voluntarily choosing to apply the program or to be observed in practice and considering the research theme is very sensitive and complex.

\section{Findings and Results}

The situation in practice proved to be diverse and complex and the variety of factors involved in building relation- 
ships were difficult to control. The way children evaluated their wellbeing or used their voices in interactions with their teachers depend on many subjective factors. But children's voices need to be heard and taken into consideration.

Findings suggested that there is no training currently available in relation to children's emotional needs. Training is focused on intellectual development. Parents claimed that they are not sufficiently involved in Kindergarten's educational programs. Unfortunately, the Romanian cultural patterns do not encourage free emotional expression. Children in our preschools rarely talk freely about their emotions. We discovered that according to the traditional attitudes of Romanian parents and practitioners, children's voices are rarely taken into consideration. The relationship between adults and children usually has rules established only for the child, not for the adult. The results proved that an investment in teacher training programs which focus on relationship skills and children's needs and rights is a significant need in the Romanian educational system. The research findings indicate that reconstructing adult's attitudes and relating styles in order to create a better world for children is necessary and urgent.

A new program was developed as a result of the training needs identified in the field. The program was focused on how practitioners and also parents should relate with children in order to listen to children's voices and to promote their wellbeing. A new model to relate was put in practice. The six steps identified by the program offers a new model to relate considered optimal in order to promote children's voice and wellbeing:

1) To smile to children while relating with them;

2) To get down physical to their level while talking or listening them;

3) To offer them models of emotional expression during daily relationships;

4) To encourage children to express their emotions by being an empathic listener;

5) To relate in a playful way learning children games to express their emotions;

6) To use emotional controls techniques during daily relationships with children.

Children's, parents' and teachers' results were similar in phase 1 in the experimental groups and the control groups.

- Many children proved that they do not have the exercise of emotional expression and need intervention to improve their social and emotional skills or behavior.

- A significant number of parents (254) signed their agreement that their children can be video recorded; only a few (18) declined.

- The new tool evaluated teachers relating skills and proved that most of them in the experimental and the control groups belong to the balanced type, but the other three types—rigid, nervous and anxious - exist too.

Important changes took place for all participants in the experimental groups while the results of the control groups remained the same: children were encouraged to talk freely about their emotions; teachers focused their attention on children's emotional needs and on the quality of their relationships, and parents were involved in promoting the program at home. In the experimental groups the program had a positive impact on all participants. In the control groups the results were similar to faze 1 .

All three hypotheses were confirmed: children's wellbeing was increased and children's voices started to be heard more, children's social and emotional skills were improved and the disruptive behaviors reduced, parents' and teachers' trust in the potential of promoting children's voice and wellbeing during the relationships increased too; the relating style was significantly improved only for teachers from the first two types (balanced and rigid) whereas for the other two (nervous and anxious) training was did not make a difference. The teachers from the balanced type get the best results.

After the new training program was put into practice in preschools and homes, teachers and parents started to give more attention to children's voices and children's wellbeing was improved. The new program helped teachers and parents to build positive and trusting relationships which improved children's wellbeing. Their attitudes made a difference depending on their relating type. The research offers a new model of building teachers' training programs. The program was proposed for a national accreditation in order to be extended to practitioners working in the Early Years all over the country.

The research program had a huge impact on teachers' and parents' perspectives on children's needs; they became more reflective and used practical models about how to become emotional trainers for children. Also, children's wellbeing was significantly improved. The need to continue the efforts to construct professional training programs for educators in the Early Years in Romania is vital in order to improve children's lives. The study is relevant in order to increase public attention to the professional development of the early childhood 
workforce as a factor that can contribute to a healthy childhood.

\section{Conclusions and Recommendations}

Children need to be listened to, valued and re-evaluated. Their rights should be respected, no matter what economic issues affect adult's lives. Children need to be respected by parents, cares and professionals, but this respect is shaped by their attitudes towards children. Certain attitudes and practices affect many children in ways that are not beneficial, and which can harm or restrict them. The language and actions of power and regulation held by adults in making and overseeing children's lives has been explored through the ways in which research, thinking and practice are reconstructing children in new ways.

By respecting children's emotional needs we have the chance to regain essential universal values for peace, justice and welfare. We must reach out with empathy to those next to us, listen to children, and fight for justice, for principles and for values. The project has had a significant impact in different areas of society: from government, to preschools and to home life. The need to invest in professional training programs for practitioners and parents is obvious in order to improve children's lives in Romania. It is the specific policy on the professionalization on this workforce which we should focus in the future.

\section{References}

Cable, C., Miller, L. (2010). Working with Children in the Early Years (2nd ed.). London and New York: Routledge Taylor \& Francis Group.

Collins, J., Foley, P. (2008). Promoting Children's Wellbeing. Policy and Practice. Milton Keynes: The Open University.

Foley, P., \& Leveret, S. (2008). Connecting with Children. Developing Trusting Relationships. Milton Keynes: The Open University.

Johnson, J. (2010). Positive and Trusting Relationships with Children in Early Years Settings. Great Britain: Learning Matters.

Jones, P. (2009). Rethinking Childhood. Attitudes in Contemporary Society. New Childhoods. New York: Continuum. 
Scientific Research Publishing (SCIRP) is one of the largest Open Access journal publishers. It is currently publishing more than 200 open access, online, peer-reviewed journals covering a wide range of academic disciplines. SCIRP serves the worldwide academic communities and contributes to the progress and application of science with its publication.

Other selected journals from SCIRP are listed as below. Submit your manuscript to us via either submit@scirp.org or Online Submission Portal.
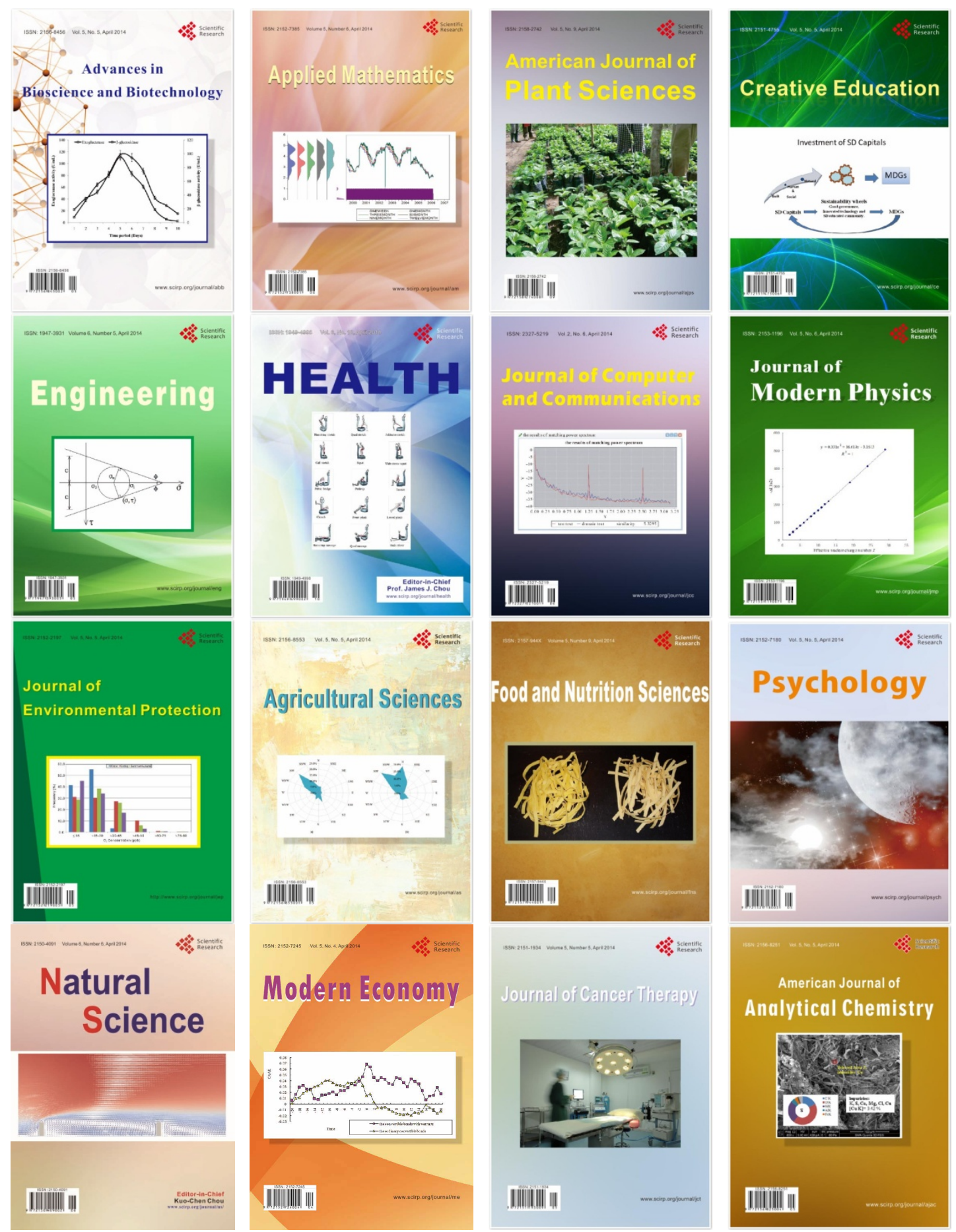